\title{
PENGEMBANGAN MANDATORI ZAKAT DALAM SISTEM ZAKAT DI INDONESIA
}

\section{ZAKAT MANDATORY DEVELOPMENT IN ZAKAT SYSTEMS OF INDONESIA}

\author{
Adang Budaya dan \\ Syamsuddin Ali Nasution
}

\author{
Magister Hukum Sekolah Pascasarjana, \\ Universitas Djuanda Bogor. \\ Korespondensi : Adang Budaya, Telp. \\ e-mail : adangbudaya@gmail.com
}

Jurnal Living Law, Vol. 13, No.

1,

2021

hlm. 1-10

\begin{abstract}
Indonesia is a country with the most Muslim population in the world. According to Global religius future, at the beginning of 2020, 87\% of its citizens were Muslims or around 209.12 million people. This is very potential for the development of zakat in Indonesia. Because basically, muzakki will still be there every year or month so that economic sustainability will be maintained and sustainable. Zakat has three fundamental functions, namely to purify the soul, blessing fortune and as an expression of social care for others. Zakat is a mandatory command of God to Muslims stated in the Qur'an and the Hadith of the Prophet Muhammad. The pillars of Islam as the five foundations of Islamic identity, are the driving force in increasing piety. Coupled with the six pillars of faith as a basic manifestation of our faith in Allah Subhanahu Wa Ta'aalaa. However, what remains a problem is that Indonesia, with the status of the largest Muslim country in the world, has not been able to break the zakat into a source of state income as well as taxes. Zakat is still voluntary. While the 2011 Zakat Law No. 23 concerning the Management of Zakat only requires amil and its management procedures, which must follow the guidelines of Islamic law.
\end{abstract}

Keywords : Zakat; Sharia; Islamic Law.

\begin{abstract}
Abstrak : Indonesia merupakan Negara dengan jumlah penduduk muslim terbanyak di dunia. Menurut Global religious future, pada awal tahun 2020, 87\% warganya beragama Islam atau sekitar 209,12 juta jiwa. Hal tersebut sangatlah potensial bagi perkembangan zakat di Indonesia. Karena pada dasarnya, muzakki akan tetap ada pada tiap tahun atau bulannya sehingga keberlanjutan ekonomi akan terus terjaga dan berkesinambungan. Zakat memiliki tiga fungsi fundamental, yaitu untuk mensucikan jiwa, keberkahan rizki dan sebagai perwujudan kepedulian sosial terhadap sesama. Zakat merupakan perintah Tuhan yang wajib kepada umat Islam yang tertuang dalam Alquran dan Hadits Nabi Muhammad. Rukun Islam sebagai lima dasar identitas keislaman, adalah motor penggerak dalam meningkatkan ketakwaan. Ditambah lagi dengan adanya rukun Iman yang enam sebagai perwujudan dasar pengimanan kita terhadap Allah Subhanahu Wa Ta'aalaa. Namun demikian, yang masih menjadi persoalan adalah Indonesia dengan status Negara muslim terbanyak di dunia belum mampu mendobrak zakat agar menjadi sumber pendapatan Negara sama halnya dengan pajak. Zakat masih bersifat sukarela. Sementara Undang-undang Zakat Tahun 2011 Nomor 23 tentang Pengelolaan Zakat hanya mewajibkan amil dan tata pengelolaannya saja yang harus mengikuti tuntunan syariat Islam.
\end{abstract}

Kata Kunci : Zakat; Syariat; Hukum Islam.

\section{PENDAHULUAN}

Masuknya Islam ke wilayah Nusantara pada awal abad ke 7 Masehi membuat peradaban kehidupan di masyarakat saat itu mengalami perubahan. Percampuran budaya, migrasi keyakinan dan tata cara ibadah benar-benar terpengaruh oleh 
adanya sejarah tiga agama besar di Nusantara, yaitu Hindu, Budha dan Islam.

Pada saat Belanda menjajah Nusantara, terutama di wilayah Kesultanan Aceh yang merupakan pintu masuk awal kolonialisme dan kapitalisme yang dimotori VOC sempat tersandung oleh adanya aktivitas zakat yang menjadi sumber perjuangan dan perlawanan terhadap penjajah. Padahal, Belanda sendiri menggunakan pajak pribumi untuk biaya perang, terutama pada masa Kesultanan Aceh Alaudin Riayat Syah antara tahun 1539-1567 masehi. Pada Masa kerajaan Aceh pengelolaan zakat masih penuh keterbatasan, yang hanya dihimpun pada masa menjelang idul fitri tiba selama bulan suci Ramadhan, yaitu zakat fitrah yang langsung diserahkan ke Meunasah (tempat ibadah seperti masjid). Pada saat itu telah didirikan Baitul Maal, namun demikian, fungsinya belum maskimal sebagai lembaga penampung zakat, infak dan sedekah, dikarenakan masih bersifat independen. Lembaga tersebut dipimpin oleh seorang wazir yang bergelar Orang Kaya Seri Maharaja. ${ }^{1}$

Dikarenakan adanya perlawanan dengan pendanaannya menggunakan dana zakat, maka kemudian Pemerintah Belanda melalui kebijakannya Bijblad No.1892 Tahun 1866 dan Bijblad No.6200 Tahun 1905 mengeluarkan kebijakan untuk melarang seluruh petugas pemerintah hindia Belanda dan masyarakat priyai untuk menunaikan zakat secara terlembaga. Peraturan tersebut berakibat terhadap penduduk di beberapa tempat yang menjadi enggan mengeluarkan zakatnya untuk diberikan kepada penghulu dan naib sebagai amil resmi pada saat itu, melainkan kepada ahli agama yang dihormati, yaitu kiyai atau guru mengaji. ${ }^{2}$ Dan kebiasaan tersebut masih terjadi hingga saat ini.

Pada tahun 1999, pemerintah melahirkan Undang-undang Nomor 38

1 Cut Hayatun Nufus, Pengelolaan Zakat di Aceh Perspektif Qanun, STEI SEBI, 2016, hlm. 27

2 Sejarah Pengelolaan Zakat Nasional, Baznas Garut, diakses pada 25 Juni 2020 Pkl.08.30 WIB
Tahun 1999 tentang Pengelolaan Zakat. Dalam Undang-Undang tersebut diakui adanya dua jenis organisasi pengelola zakat yaitu Badan Amil Zakat (BAZ) yang dibentuk pemerintah dan Lembaga Amil Zakat (LAZ) yang dibentuk oleh masyarakat dan dikukuhkan oleh pemerintah. BAZ terdiri dari BAZNAS pusat, BAZNAS Propinsi, dan BAZNAS kabupaten/kota.

Sebagai implementasi UU Nomor 38 Tahun 1999 dibentuk Badan Amil Zakat Na-sional (BAZNAS) dengan Surat Keputusan Presiden Republik Indonesia Nomor 8 Tahun 2001. Dalam Surat Keputusan ini disebutkan tugas dan fungsi BAZNAS yaitu untuk melakukan penghimpunan dan pendayagunaan zakat. Langkah awal adalah mengupayakan memudahkan pelayanan, BAZNAS menerbitkan nomor pokok wajib zakat (NPWZ) dan bukti setor zakat (BSZ) dan bekerjasama dengan perbankan dengan membuka rekening penerimaan dengan nomor unik yaitu berakhiran 555 untuk zakat dan 777 untuk infak. Dengan dibantu oleh Kementerian Agama, BAZNAS menyurati lembaga pemerintah serta luar negeri untuk

Mandat BAZNAS sebagai koordinator zakat nasional menjadi momentum era Kebangkitan Zakat di Indonesia. Dengan berharap Rahmat dan Ridha Allah Ta'alaa, semoga kebangkitan zakat mampu mewujudkan stabilitas negara, membangun ekonomi kerakyatan, dan mengatasi kesenjangan sosial.

\section{METODE PENELITIAN}

Metode Penelitian ini menggunakan 2 (dua) pendekatan yaitu yuridis normatif (doktrinal) dan yuridis empiris (nondoktrinal),

Dalam kajian komparasi atau penelitian dilakukan dengan membuat perbandingan hukum. Sebagaimana dikemukakan oleh Kokkini-latridou yang menyatakan: "No matter how systematically it is carried out, research cannot be described as being 'comparative' if it does 
not give an 'explanation' of the similarities and differences" (tidak peduli seberapa sistematis itu dilakukan, penelitian tidak dapat digambarkan sebagai makhluk 'komparatif' jika tidak memberikan 'penjelasan' tentang persamaan dan perbedaan). ${ }^{3}$ Kajian ini apabila dilakukan oleh seluruh pemangku kepentingan tentunya akan menciptakan sebuah hasil observasi yang komprehensif dan mampu menciptakan sebuah aturan yang benar dibutuhkan oleh masyarakat.

\section{PEMBAHASAN}

\section{A. PENGERTIAN ZAKAT}

Menurut bahasa, zakat berasal dari kata "zaka" yang artinya berkah, tumbuh, bersih dan baik. Sedangkan menurut bahasa Arab, arti dasar dari kata zakat, ditinjau dari segi bahasa adalah, suci, tumbuh, berkah dan terpuji. Semua arti dari zakat tersebut telah disebutkan dalam Alquran dan Hadits. Zakat dalam istilah fiqih berarti sejumlah harta tertentu yang diwajibkan Allah Subhanahu Wa Ta'aalaa diserahkan kepada orang-orang yang berhak. ${ }^{4}$

Ditinjau dari segi bahasa, kata zakat merupakan kata dasar (masdar) dari zaka yang berarti berkah, tumbuh, bersih, dan baik. Sesuatu itu zaka, berarti tumbuh dan berkembang, dan seorang itu zaka, berarti orang itu baik. Tetapi yang terkuat, menurut Wahidi, kata dasar zaka bermakna bertambah atau tumbuh, sehingga bisa dikatakan, tanaman itu zaka, artinya tumbuh, sedangkan tiap sesuatu yang bertambah disebut zaka artinya bertambah. Apabila satu tanaman tumbuh tanpa cacat, maka kata zaka disini berarti bersih. Dan bila seseorang diberi sifat zaka dalam arti baik, maka berarti orang itu lebih banyak mempunyai sifat yang baik. Seorang itu zaki, berarti seorang yang

3 Danu Suryani \& Endeh Suhartini, Jurnal Hukum De'rechtsstaat. P-ISSN:2442-5303. E-ISSN:25499874. Volume 4 No. 2, September 2018, hlm. 107

4 M. Yusuf Qardawi, Hukum Zakat, Litera Antar Nusa, Bogor, 1999, hlm. 34 memiliki lebih banyak sifat-sifat orang baik, dan kalimat "hakim-zaka-saksi" berarti hakim mengatakan jumlah saksisaksi diperbanyak. ${ }^{5}$ Zakat dari segi istilah fikih berati "sejumlah harta tertentu yang diwajibkan Allah diserahkan kepada orangorang yang berhak" di samping berarti "mengeluarkan jumlah tertentu itu sendiri". Jumlah yang dikeluarkan itu disebut zakat karena yang dikeluarkan itu bertambah banyak, membuat lebih berarti, dan melindungi kekayaan itu dari kebinasaan. ${ }^{6}$ Dalam Islam kita harus mematuhi segala hukum yang berlaku, semua perintah dalam agama harus dijalankan tak terkecuali dengan kita mengeluarkan harta yang kita miliki dengan ukuran yang telah ditentukan kepada orang-orang yang berhak atau lebih kita kenal dengan istilah zakat tersebut.

Menurut Didin Hafidhudin, dilihat dari segi bahasa, zakat memiliki beberapa makna, yakni Al-Baraktu "keberkahan", AlNamaa "pertumbuhan dan perkembangan," Ath-Thaharatu, kesucian, dan Ash-Shalahu "keberesan". Sedangkan secara istilah yaitu bahwa zakat merupakan bagian dari harta dengan syarat-syarat tertentu yang Allah Ta'aalaa wajibkan kepada pemiliknya untuk diserahkan kepada yang berhak menerimanya dengan syarat-syarat tertentu pula. ${ }^{7}$

\section{B. SEJARAH SINGKAT ZAKAT SEBELUM ISLAM}

Sejarah tentang praktek zakat tidak hanya berlaku pada masa Rasulullah Shallallahu 'Alaihi Wa Sallam saja, Alquran menjelaskan kejadian masa lalu tentang praktek zakat agama samawi sebelum umat Muhammad. Misalnya, sebagaimana penjelasan berikut di bawah ini:

a. Zakat Semasa Nabi Ibrahim a.s

Pada masa Nabi Ibrahim, disebutkan dalam Alquran surat Al-Anbiya' bahwa

\footnotetext{
${ }^{5}$ Ibid

6 Ibid

7 Didin Hafidhuddin, Zakat dalam Perekonomian Modern, Gema Insani, Jakarta, 1998, hal. 7
} 
zakat telah disyari'atkan kepada Nabi Ibrahim, lalu diteruskan kepada anaknya, Nabi Ishaq, dan kepada anaknya lagi, Nabi Ya'kub a.s serta kepada masing-masing umat mereka. (Al Anbiya' : 73) ${ }^{8}$

b. Zakat Semasa Nabi Ismail a.s

Putra Nabi Ibrahim itu ada dua, Ishak dan Ismail. Meski terpaut usia jauh diantara mereka, Namun Allah Subhanahu Wa Ta'aalaa mensyari'atkan ibadah zakat kepada Ismail. Hal ini disebutkan dalam Alquran Surat Maryam ayat $55^{9}$. (Maryam : 55)

c. Zakat Kaum Yahudi

Praktek zakat kaum Yahudi dan Bani Israel dijelaskan dalam Alquran surat Al-Baqarah ayat 83.10

Menurut ajaran Yahudi terdapat sebuah istilah "tzedakah" yang didasarkan pada bahasa Ibrani (tzedek), artinya kewajiban agama untuk melakukan apa yang benar dan adil. Tidak seperti filantropi atau amal yang benar-benar suakarela, tzedakah dipandang sebagai kewajiban agama yang harus dilakukan terlepas dari kondisi keuangan, bahkan orang-orang miskin. Kewajiban ini bersifat individual dan minimal dalam jumlah 10 persen. ${ }^{11}$

d. Zakat Kaum Nasrani

Dijelaskan dalam kitab suci Alquran surat Maryam ayat $31{ }^{12}$ bahwa Nabi Isa a.s terkena pula kewajiban shalat dan zakat.

\section{PERINTAH ZAKAT DALAM AL-QURAN DAN HADITS}

Op. Cit, Muhammad Thalib, hlm. 328-329

Ibid, hlm. 310

10 Ibid, hlm. 13

11 Lihat http://www.judaism-islam.com/tsedakahzakah-sadaqah-the-law-of-charity-in-islam-andjudaism/\#sthash.wDg|kmEo.dpuf. Lihat juga http://www.jewfaq.org/tzedakah.htm diakses pada tanggal 14 Mei $2020 \mathrm{Pkl} .15 .00 \mathrm{WIB}$

12 Loc. Cit, Muhammad Thalib, hlm. 308
Hubungan antara pengertian zakat menurut bahasa dengan pengertian menurut istilah, sangat nyata dan erat, yaitu bahwa harta yang dikeluarkan zakatnya akan menjadi berkah, tumbuh, berkembang dan bertambah, suci dan beres (baik). Zakat wajib ini menururt Alquran juga disebut sedekah, sehingga sedekah itu adalah zakat dan zakat itu adalah sedekah, berbeda nama tetapi sama artinya, namun memiliki syarat dan ketentuan yang berbeda. ${ }^{13}$ Ada beberapa Firman Allah Ta'aalaa yang menyebutkan bahwa sedekah sama dengan zakat antara lain :

a) Q.S. At-Taubah ayat 58

b) Q.S. At-Taubah ayat 60

c) Q.S. Al An'am (6) ayat 141

Beberapa ayat di atas adalah tentang zakat, tetapi diungkapkan dengan istilah sedekah. Namun, dalam penggunaaan sehari-hari kata sedekah itu disalah artikan yaitu hanya berarti sedekah yang dituliskan kepada pengemis dan peminta-minta. ${ }^{14}$

Perintah kewajiban zakat salah satunya terdapat dalam hadits riwayat Muslim ${ }^{15}$ dari Abu Hurairah Radhiyallahu'anh. Hukum, Syarat, dan Rukun Zakat Maal (Harta), Berikut penjelasan tentang hukum, syarat dan rukun zakat mal :

a. Hukum Zakat Harta

Hukum zakat mal (harta) adalah fardhu 'ain ${ }^{16}$ atau wajib bagi siapapun yang kekayaannya sudah mencapai ukuran satu haul atau nishab (batas minimal harta yang sudah wajib dikeluarkan zakatnya.). Hal ini seperti yang dijelaskan dalam Alquran surat At-Taubah (9) ayat 103:

"Ambillah zakat dari sebagian harta mereka, dengan zakat itu kamu

13 Hasil wawancara pada tanggal 2 Juni 2020 Pkl.18.30 WIB. dengan Maizar Madsury sebagai Ketua Majelis Tabligh PDM Kota Bogor,

14 Zalikha, Pemberian Sumbangan Pada Pemintaminta Pasca Panen Padi, Jurnal Al-Bayan, Vol. 2, No. 33, Januari-Juni 2016, hlm. 84

15 Tafsirq, Kitab Shahih Bukhari Muslim Nomor 16, hlm. 2

16 https://www.muslim.or.id diakses pada 21 Juni 2020 Pkl.06.15 WIB 
membersihkan dan mensucikan mereka dan mendoalah untuk mereka".

Orang yang enggan menunaikan zakat dalam keadaan meyakini wajibnya, ia adalah orang fasik dan akan mendapatkan siksa yang pedih di akhirat. Allah Ta'ala berfirman:

"Dan orang-orang yang menyimpan emas dan perak dan tidak menafkahkannya pada jalan Allah, maka beritahukanlah kepada mereka, (bahwa mereka akan mendapat) siksa yang pedih, pada hari dipanaskan emas perak itu dalam neraka jahannam, lalu dibakar dengannya dahi mereka, lambung dan punggung mereka (lalu dikatakan) kepada mereka: "Inilah harta bendamu yang kamu simpan untuk dirimu sendiri, maka rasakanlah sekarang (akibat dari) apa yang kamu simpan itu." (QS. At Taubah: 34-35).

b. Syarat Wajib Zakat Harta dan Harta Yang Wajib Dizakati. Fiqih zakat telah menjelaskan syarat-syarat yang wajib terpenuhi dalam mengeluarkan zakat, yaitu:

i. Syarat wajib zakat harta :

1. Islam.

2. Merdeka.

3. Harta yang dizakatkan adalah milik pribadi (bukan harta orang lain).

4. Harta yang yang hendak dizakatkan sudah memenuhi satu nishab.

5. Sudah mencapai satu tahun.

ii. Syarat-syarat harta yang wajib dizakati :

1. Milik Penuh

2. Berkembang

3. Mencapai Nishab

4. Lebih Dari Kebutuhan Pokok.

5. Bebas dari Hutang.

6. Berlalu Satu Tahun (Haul)

c. Rukun Zakat Harta

Adapun rukun zakat adalah sebagai berikut :
1. Niat

2. Muzakki (Orang yang berzakat)

3. Mustahik (Orang yang menerima zakat)

a. Makanan pokok yang dizakatkan.

\section{JENIS-JENIS HARTA YANG WAJIB DIZAKATI}

Jenis-jenis harta yang wajib untuk dikeluarkan zakatnya adalah :

a. Zakat Emas dan Perak

b. Zakat Binatang Ternak (sapi/kerbau, unta, kambing/domba).

c. Zakat Hasil Pertanian.

d. Zakat Profesi.

e. Zakat Perniagaan.

f. Zakat Rikaz.

g. Zakat Barang Tambang.

\section{E. ORANG-ORANG YANG BERHAK MENERIMA ZAKAT DAN HARAM DIZAKATI}

a. Orang-orang Yang Berhak Menerima Zakat

Terdapat 8 golongan yang termasuk orang-orang yang berhak menerima zakat. ${ }^{17}$ Allah Subhanahu Wa Ta'aalaa telah memberikan jaminan untuk menjelaskan siapa saja orang-orang yang berhak menerima zakat. Hal ini tercantum dalam firman Allah pada surat At-Taubah ayat 60, antara lain :
1. Orang Fakir
2. Orang Miskin
3. Amil Zakat
4. Muallaf
5. Riqab
6. Gharim ( Orang yang berhutang)
7. Fii sabilillah
8. Ibnu sabil

b. Orang-orang yang haram menerima zakat:

1. Orang yang kaya dengan harta atau kaya dengan usaha dan penghasilan.

\footnotetext{
17 Ibid, hlm. 309.
} 
2. Hamba sahaya yang mendapatkan nafkah dari tuanya. ${ }^{18}$ termasuk Bani Muthalib, Bani Hasyim, Bani Naufal, Bani Syam dan istri-istri Rasulullah ${ }^{19}$.

3. Orang yang dalam tanggungan zakat, maksudnya tidak boleh memberikan zakat terhadap orang yang masih menjadi tanggungan orang yang berzakat. ${ }^{20}$

4. Orang yang tidak beragama Islam. ${ }^{21}$

\section{F. PENYEBAB SISTEM ZAKAT DI INDONESIA BELUM MENGANUT SISTEM MANDATORI PADAHAL NEGARA INDONESIA MERUPAKAN NEGARA PENGANUT ASAS PANCASILA}

Adapun hal-hal yang menyebabkan sistem zakat di Indonesia belum bersifat mandatori adalah sebagai berikut :

1. Kepercayaan ,masyarakat masih kurang terhadap lembaga pengelola zakat baik pemerintah maupun swasta.

2. Pemerintah dan lembaga legislatif belum berani membuat sebuah aturan yang tegas tentang kewajiban membayar zakat bagi warga muslim yang mampu dan memberikan kompensasi bagi keringan pajak yang lebih besar bagi yang membayar zakat atau bahkan hingga mengkonversi pajak ke zakat bagi seorang muslim yang membayar zakat dengan kriteria tertentu.

3. Pendistribusian zakat didominasi oleh kegiatan-kegiatan karitatif,

18 Lihat al-Mugni (4/106-107) dan asy-Syarhul Mumti' (6/264-266)

19 https://asysyariah.com/golongan-yang-tidakberhak-menerima-zakat/ diakses pada 21 Juni 2020 Pkl.19.05 WIB

20 Lihat al-Mughni (4/98-100), al-Majmu' (6/222223), Majmu' al-Fatawa (25/90-93), alIkhtiyarat hal. 61-62, Nailul Authar (4/178-179), dan asy-Syarhul Mumti' (6/251-253, 262-263).

21 http://asysyariah.com/golongan-yang-tidakberhak-menerima-zakat/ diakses pada 03 Nopember 2019 Pkl.18.34 WIB
Adapun Kelemahan lain yang bersifat teknis yang perlu diperhatikan adalah sebagai berikut :

a. BAZNAS belum memiliki sistem data (database) yang pasti dan akurat tentang data muzakki yang berskala nasional yang mudah diakses masyarakat. Sementara yang ada dan massive dipublikasikan hanya informasi layanan penerimaan zakat, hasil pengumpulan dana zakat dan deskripsi kegiatan dalam rangka pendistribusian dana zakat.

b. Kurangnya political will ${ }^{22}$ dalam rangka menjalankan fungsi pengawasan dan penegakkan hukum/sanksi terhadap segala bentuk penyelewengan pengelolaan dan pendistribusian dana zakat, serta dalam rangka membangun kesadaran masyarakat yang majemuk dengan segala karakter dan kepribadiannya sesuai dengan pola hidup masyarakat itu sendiri.

\section{G. PENGEMBANGAN POTENSI ZAKAT DI INDONESIA DALAM RANGKA MEMBANGUN KETAHANAN EKONOMI RAKYAT, KHUSUSNYA UMAT ISLAM}

Berikut beberapa strategi pengembangan potensi zakat di Indonesia dalam rangka membangun ketahanan ekonomi umat Islam :

1. Membudayakan membayar zakat. Menumbuhkan dan mengembangkan kesadaran membayar zakar tidak hanya terfokus kepada muzakki yang telah rutin membayarkan kewajiban zakatnya, meskipun mereka adalah bagian yang harus dijaga dan dirawat dalam menjalin hubungan antara muzakki dan lembaga yang melayani, namun demikian, seluruh lapisan masyarakatpun harus menjadi bagian yang wajib dibina sedini mungkin. Para amil mendapatkan pembinaan skill modern dalam rangka optimalisasi

22 Hasil wawancara degan Ketua Bidang Dakwah PDM Kota Bogor, Ustazh Maizar Madsury Lc, pada tanggal 18 Mei 2020 Pkl.16.00 WIB 
pendayagunaan media digital atau aktifitas berbasis teknologi. Namun demikian, adakalanya amil harus datang menjemput bola untuk membantu memverfikasi data muzakki dan menghitung kewajiban zakat.

2. Adanya perluasan bentuk penyaluran atau pendistribusian. Merubah paradigma manajemen yang hanya mengandalkan asas "Lillahi Ta'aalaa" tanpa substansi dari makna yang terkandung dalam pernyataan tersebut. Maka akan lebih sempurna apabila konsep "Lillahi Ta'aalaa" tersebut didukung oleh aspek lainnya yang juga sangat berkaitan erat dalam peningkatan etos kerja, yaitu akuntabel, profesional, amanah, dan memiliki integritas tinggi dalam menjalankan tugasnya sebagai bagian dari pengelola zakat.

3. Membagi kefokusan dalam pemetaan program.

4. Daya jangkau pendistribusian dana zakat bisa mencakup kebutuhan warga negara diluar negeri yang membutuhkan.

5. Dana zakat digunakan untuk pengembangan usaha kreatif-produktif agar dapat mengurangi dominasi pasar asing dan investasi-investasi asing yang justru merugikan masyarakat, dan hal ini juga bisa digunakan untuk menyentuh perluasan jaringan usaha halal.

Selama proses penelitian, ada beberapa fakta lapangan yang ditemukan terkait dengan persepsi masyarakat terhadap pelaksanaan pengelolaan zakat yang dilakukan oleh lembaga amil zakat, dalam hal ini adalah BAZNAS. Sekurangkurangnya terdapat tiga informasi yang didapat.

Pertama, belum adanya koordinasi yang terintegritas antara antara Dinas Sosial, lembaga sosial swasta dan Badan Amil Zakat secara kuat.

Kedua, Kementerian Agama di daerahdaerah sebagai kepanjangan tangan
Pemerintah pusat mendapati temuan bahwa Baznas, UPZ, LAZ berjalan sendirisendiri tanpa adanya kefokusan dalam menjalankan program pendistribusian dana zakat secara tepat dan menjangkau lebih luas. ${ }^{23}$

Ketiga, Baznas sebagai bagian dari koordinator lembaga pengelola zakat mewakili pemerintah, masih cukup pasif dalam menjalankan fungsinya dalam mengawal lembaga pengelola zakat swasta atau nonpemerintah, bahkan menurut fakta di lapangan antara Baznas dan lembaga amil zakat swasta terkesan berkompetisi, padahal seharusnya adalah sinergitas dan berkolaborasi. ${ }^{24}$

\section{KESIMPULAN}

Berdasarkan uraian yang telah dijelaskan pada bab-bab sebelumnya, maka dapat ditarik kesimpulan sebagai berikut:

1. Penyebab sistem zakat di Negara Indonesia yang belum bersifat mandatori, padahal Negara Indonesia menganut asas Pancasila yaitu ; Pertama, belum adanya political will state (kemauan politik dari negara). Negara Indonesia belum memiliki regulasi atau UU Zakat yang mewajibkan, sementara payung hukum zakat di Indonesia yang ada adalah UU Zakat Nomor 23 Tahun 2011 Tentang Pengelolaan Zakat masih bersifat sukarela dan parsial. Artinya sukarela adalah setiap warga muslim di Indonesia hanya dianjurkan/dihimbau untuk membayar zakat, dan tidak ada sanksi bagi yang enggan menunaikannya. Sementara parsial adalah kewajiban menjalankan pengelolaan dan pendistribusian zakat harus berdasarkan tuntunan syari'at

23 Informasi berdasarkan hasil wawancara dengan Pejabat Pengelola Zakat kementerian Agama Kota Bogor, pada tanggal 01 Nopember Pkl.14.00 WIB

24 Informasi berdasarkan hasil wawancara dengan komisioner Baznas Kota Bogor, pada tanggal 17 Mei 2020 Pkl.14.00 WIB 
Islam hanya dibebankan kepada lembaga amil zakat dan amil zakat saja, dan bagi siapapun yang melakukan pelanggaran maka kepadanya diberlakukan sanksi baik secara administrasi maupun pidana. Kedua, belum kuatnya political society (kemauan yang kuat dari masyarakat). Pengamalan Pancasila terutama sila Ke-1 "Ketuhanan Yang Maha Esa" dan UUD 1945 Pasal 29 ayat (2) belum seluruhnya menjadi ruh pengimplementasian nilai-nilai keagamaan dalam kehidupan seharihari karena tingkat pemahaman masyarakat terhadap agamanya masih perlu ditingkatkan dalam rangka membangun awareness (kesadaran) untuk menumbuhkan rasa kepedulian sosial dan menumbuhkan keimanan, keikhlasan serta ketakwaan kepada Tuhan Yang Maha Esa. Dan tentunya, hal ini merupakan upaya untuk menyeimbangkan hablumminallah (hubungan dengan Allah) secara vertikal dan hablumminnaas (hubungan dengan manusia) secara horizontal dengan konsep dasar "khairunnas anfa'uhum linnaas" untuk menjadi pribadi yang bermanfaat bagi manusia lainnya.

2. Pengembangan potensi zakat di Indonesia dalam rangka membangun ketahanan ekonomi rakyat, khususnya umat Islam. Hal ini dapat dilakukan dengan cara-cara strategis sebagai berikut ; Pertama, tersedianya Bank Data (database) mustahiq dan muzakki yang mudah diakses oleh masyarakat umum. Langkah ini sangat perlu untuk diprioritaskan dalam rangka membangun kepercayaan masyarakat terhadap lembaga zakat yang profesional, akuntabel, transparan dan amanah. Kedua, Pendistribusian dana zakat harus diperluas dengan memperbanyak kegiatan-kegiatan produktif berdasarkan asas kemanfaatan yang berkesinambungan, khususnya dalam pengembangan keahlian masyarakat (life skill). Hal ini dilakukan dalam rangka mengurangi karakter masyarakat yang konsumtif dan membangun SDM yang unggul dan produktif, sehingga pada akhirnya lembaga pengelola zakat akan mampu menumbuhkan individu-individu yang tadinya berstatus mustahik menjadi muzakki, dan ini sangat berdampak terhadap penurunan angka kemiskinan. Ketiga, selain berlandaskan ikhlas dan menjalankan kewajiban karena Allah semata, namun perlu dibangun dan dibentuk kualitas maupun kapabilitas, intelektual dan ilmu pengetahuan amil/pengelola zakat yang mumpuni sehingga kemudian dapat mentransfernya kembali ke masyarakat. Dengan tingkat pemahaman yang tinggi tentunya akan memacu peningkatan sumber pendapatan zakat yang lebih maksimal dan penyaluran yang lebih tepat. Keempat, membangun infrastruktur kesehatan, rumah pelatihan keahlian mandiri, dan permodalan ringan bagi para pelaku usaha kecil menengah agar dapat bertahan dan tumbuh menjadi penyeimbang pasar, upaya ini dilakukan untuk mengurangi dominasi pasar bebas yang dikuasai asing dan mendukung pemenuhan produk halal dengan sertifikasi halal gratis atau subsidi bagi yang tidak mampu, serta pengadaan bahan-bahan pokok halal bagi masyarakat, Kemudian perlunya perluasan pembangunan infrastrukur yang berjangka panjang, seperti rumah sakit/klinik gratis bagi warga miskin dan infrastruktur penunjang sosial lainnya yang disesuaikan dengan kebutuhan masyarakat muslim.

Realisasi pengembangan potensi zakat harus menjadi kefokusan tersendiri dan masih menjadi pekerjaan rumah yang besar bagi umat Islam. Karena untuk mencapai hal tersebut, perlu keinginan yang kuat, kesadaran yang tinggi dan kerja bersama antara stakeholder, para tokoh dan masyarakat muslim pada umumnya. 
Karena apabila ini dikehendaki oleh mayoritas umat Islam bisa menjadi sebuah pertimbangan untuk segera direalisasikan, karena hukum pada dasarnya bersifat bottom up. ${ }^{25}$

\section{SARAN}

Berdasarkan hasil penelitian yang telah dilakukan pada bab-bab sebelumya, mengenai Pengembangan Mandatori Zakat Dalam Sistem Zakat di Indonesia, serta merujuk pada kesimpulan diatas maka ada beberapa saran dan rekomendasi, yang antara lain adalah :

1. Kepada pemerintah dan DPR RI perlu membuat sebuah rancangan peraturan atau RUU yang lebih spesifik dan tegas mengatur tentang wajibnya zakat bagi semua umat muslim yang mampu. Apabila dalam UUZ 23/2011 telah diatur pewajiban menjalankan pengelolaan zakat dan amil harus berdasarkan tuntunan syari'at Islam dan pengurangan kewajiban pajak bagi yang membayar zakat, begitupun dengan pewajiban untuk membayar zakat bagi setiap individu muslim di Indonesi yang dianggap mampu berdasarkan ketentuan agama dan negara harus diatur dan diwajibkan pula. Mengingat mayoritas umat Islam bisa menjadi potensi dan investasi yang berkelanjutan dalam mempercepat proses pembangunan Negara yang memiliki kekuatan ekonomi kerakyatan yang mandiri, salah satunya ekonomi berbasis syari'ah.

2. Kepada lembaga pengelola zakat, khususnya BAZNAS agar dapat mensosialisasikan kewajiban zakat kepada seluruh lapisan masyarakat,

25 Hukum diadakan untuk mengatur masyarakat, dan masyarakat wajib mentaatinya demi ketertiban semua. Hukum berkaitan erat dengan corak hidup dan kebutuhan masyarakat. Lihat Buku Adagium Hukum tentang UBI SOCIETAS IBI JUS (Dimana ada masyarakat disitu ada hukum) dan LEX SEMPER DABIT REMEDIUM (Hukum harus selalu memberi obat). tidak hanya berbasis teknologi, namun juga berbasis kultural/tradisional secara humanistis agar dapat menembus setiap tingkatan masyarakat. Kepada akademisi, agar dapat menjadikan hasil penelitian ini sebagai bagian dari bahan untuk penelitian berikutnya dalam rangka memperbaiki dan membuat karyakarya ilmiah lainnya sebagai masukan dan kritik konstruktif kepada pemerintah tentang zakat berdasarkan perkembangan zaman dan sebagai bahan untuk memberikan saran dan rekomendasi kepada stakeholder sehingga terbangun kesadarannya tentang betapa besar pengaruhnya potensi zakat bagi perekonomian bangsa, khususnya umat Islam. 


\section{DAFTAR PUSTAKA}

Adang Purnama, Martin Roestamy, Efektivitas Penyelesaian Sengketa Fidusia Terhadap Penyerahan Jaminan Fidusia Kredit Mikro, Jurnal Living Law ISSN 2087-4936 Vol. 8, No. 1, Januari 2016

Danu Suryani \& Endeh Suhartini, Jurnal Hukum De'rechtsstaat. P-ISSN:2442-5303. EISSN:2549-9874. Volume 4 No. 2, September 2018

Quthub, Sayyid , Tafsir Fii Dzilalil Qur'an di Bawah Naungan Alquran, Tafsir Fii Dzilalil Quran, Beirut, Jilid I

Roestamy, Martin, dkk, Pedoman Penulisan Skripsi Pada Fakultas Hukum, Fakultas Hukum Unida Bogor, Bogor, 2015

SA Nasution, Signifikansi Disiplin belajar Terhadap Hasil Belajar Mata Pelajaran Akidah Akhlak, Tadbir Muwahhid ISSN 2579-4876 e-ISSN 2579-3470 Vol. 1, No. 2, 2017

Thalib, Muhammad, Alquranul Karim, Tarjamah Tafsiriyah, Memahami Makna Alquran Lebih Mudah, Cepat dan Tepat, Yogyakarta, Ma'had An-Nabawy,Yayasan Ahlu Shuffah, 2011

$\underline{\text { http://baznas.go.id }}$

http://baznaskotabogor.go.id

http://baznaskabbogo 